\title{
Uma Nova Classe Média no Brasil da Última Década? O debate a partir da perspectiva sociológica
}

Celi Scalon
André Salata $^{2}$

Resumo: Este artigo analisa o surgimento de uma nova classe média, como vem sendo proposto pelos economistas brasileiros, à luz da perspectiva sociológica dos Estudos de Classe. Para tanto, recupera o debate da Economia, que se baseia na renda para definir classes, assim como o da Sociologia da Estratificação, de acordo com seus diferentes marcos teóricos. Usando dados das PNADs 2002 e 2009, apresenta o argumento de que as mudanças na estrutura de classes não foram significativas a ponto de apoiar a ideia de uma nova classe, nem houve um crescimento na classe média tradicional.

Palavras-chave: Classe Média, Desigualdades, Estratificação, Renda, Consumo.

Apresentação



as últimas décadas, não houve momento mais oportuno do que este para falar sobre a classe média no Brasil. Atualmente, o debate em torno desse tema é tão intenso que tem ultrapassado os limites da academia e se espraiado, através do debate público, para os jornais impressos, revistas, televisão, etc. De uma maneira geral, tem sido constantemente defendida a ideia de crescimento da classe média no Brasil ou, até mesmo, de surgimento de uma nova classe média.

Não são raras as reportagens a respeito de famílias que, devido a melhorias em sua renda, vêm aumentando o padrão de consumo e conquistando espaço em mercados antes exclusivos a setores mais abastados. Exemplos que têm servido para ilustrar a ideia de que o Brasil teria se tornado um país composto, em sua maioria, por famílias de classe média.

Este debate foi, em grande parte, impulsionado por recentes trabalhos de acadêmicos que definem as classes exclusivamente, ou em parte, através da renda ou do acesso ao consumo (TORRES, 2004; NERI, 2008; SOUZA \& LAMOUNIER, 2010; OLIVEIRA, 2010).
1. Professora titular da UFRJ.

E-mail: celiscalon@ gmail.com

2. Doutorando do PPGSA/IFCS/UFRJ E-mail: andre_salata@ yahoo.com.br 
3. Ver também reportagem publicada no jornal $O$ Globo em 06/08/2008, intitulada "Educação e Trabalho são os Símbolos da Classe Média". Endereço eletrônico: http://oglobo.globo.com/economia/ mat/2008/08/06/ educacao_trabaIho_sao_os_simbo los_da_classe_media-547610026.asp
Nos últimos anos, o país apresentou taxas de considerável crescimento econômico que, aliadas à diminuição das desigualdades de rendimentos, aos programas de transferência de renda, à estabilização econômica alcançada nas últimas décadas e à expansão do crédito, têm sido capazes de elevar os rendimentos e o padrão de consumo de muitas famílias (BARROS et al., 2010). Tomando como base esse cenário economicamente positivo, o trabalho de Neri (2008) mostrou a diminuição dos grupos de renda inferiores e o correlato crescimento dos grupos intermediários - a chamada "nova classe média".

No entanto, apesar da enorme importância da remuneração, partindo do ponto de vista sociológico, talvez esse não seja o critério mais adequado para se atestar o crescimento ou diminuição da classe média. O aumento da renda e do consumo não retrata, necessariamente, mudanças na composição das classes, muito menos no que diz respeito às desigualdades nas chances de vida. Com base em argumentos semelhantes, alguns sociólogos, inclusive, já vêm questionando a tese da "nova classe média" brasileira e suas conclusões (SOUZA, 2010; SOBRINHO, 2011).

No presente trabalho, temos como aprofundar essa discussão, ao analisar, através de um prisma mais sociológico, a relação entre essas mudanças na distribuição de renda e possíveis alterações na estrutura de classes.

\section{A Tese da Nova Classe Média}

Mudanças significativas vêm ocorrendo em relação à distribuição de renda na sociedade brasileira (BARROS et al., 2010). Desde 2001, o índice Gini, uma das medidas mais tradicionais de desigualdade de renda, vem caindo continuadamente, alcançando os menores valores das últimas três décadas. Nos últimos anos, a renda dos mais pobres cresceu de forma substantiva, acarretando um declínio dos níveis de pobreza e miséria.

Seja do ponto de vista da distribuição de renda, da diminuição de pobreza, ou do crescimento do emprego e da formalidade no mercado de trabalho, a última década trouxe melhorias significativas para uma grande parte da população brasileira. Diante de dados como esses, como já tivemos a oportunidade de mostrar, alguns autores vêm defendendo a ideia de que estaria se desenvolvendo no Brasil, como resultado dessas melhoras, uma expansão da classe média.

O estudo coordenado por Neri (2008), grande propulsor do debate sobre o crescimento da classe média brasileira nos últimos anos, se baseia no chamado "Critério Brasil" e divide a sociedade brasileira em 4 faixas ( $A B, C, D$, e $E$ ), cujos limites são dados pela renda, tomando como referência algumas medidas, 
como mediana, decis, ou linha de miséria. Assim, pesquisa da FGV toma os dados sobre o crescimento da "Faixa C" - que se encontra entre a mediana e o nono decil da distribuição, ou seja, entre os "remediados" e a "elite" -, como crescimento da classe média. Compreendida entre os $50 \%$ mais pobres e os $10 \%$ mais ricos, a "Faixa C" aufere a renda média da sociedade. Por essa razão, Neri (2008), em alguns trechos, a define como "classe média no sentido estatístico (...) imagem mais próxima da sociedade brasileira" (p. 5).

No entanto, como também foi identificado por Sobrinho (2011), há muita imprecisão nos argumentos de Neri (2008), principalmente em sua definição de "classe média". Se, empiricamente, a definição se dá unicamente através da renda, a ideia por trás dessa abordagem inclui, também, poder de consumo, posição na ocupação, investimento em educação, plano de saúde e carteira de trabalho assinada. Porém, o único resultado ao qual os dados apresentados por Neri (2008) podem nos levar é o de que houve, nos últimos anos, no Brasil, aumento da participação dos grupos de renda intermediário. Falar, a partir daí, de crescimento da classe média, exigiria, no mínimo, um maior diálogo com a extensa literatura sociológica sobre o tema - que analisaremos rapidamente na seção seguinte.

\section{Em Busca de uma Definição Conceitual para “Classe(s) Média(s)”}

A discussão sociológica em torno da definição de "classe média" é complexa, ainda que não seja recente. Já em Marx, podemos encontrar citações a respeito dos grupos intermediários, sejam eles a pequena burguesia proprietária ou os empregados assalariados, supervisores, técnicos, etc. (BURRIS, 1986). Weber, por outro lado, ao longo de quase toda sua obra, esteve atento ao desenvolvimento da autoridade impessoal e racional através da formação das burocracias, em grande parte responsáveis pelo crescimento da chamada nova classe média, na primeira metade do século XX (MILLS, 1951).

Mills (1951) descreve muito bem esse processo e faz um abrangente estudo da formação da nova classe média nos Estados Unidos da América. Sob influência de Weber, Mills analisa a diminuição da antiga classe média - composta pelos pequenos proprietários -, e o enorme crescimento da nova classe média (whitecollar workers) - administradores, gerentes, supervisores, técnicos, trabalhadores de escritório, vendedores, etc. -, nos Estados Unidos da primeira metade do século XX.

Uma das grandes dificuldades, principalmente dentro do campo marxista, para lidar com as chamadas novas classes médias, é o fato de seus integrantes não serem proprietários, mas ao mesmo tempo administrarem os negócios, fazerem trabalhos não manuais, supervisionarem os trabalhadores ou possuírem 
4. Esse termo foi cunhado por Karl Renner e utilizado, também, no trabalho de Dahrendorf (1950), que, notavelmente, teve influência sobre o trabaIho de Goldthorpe. habilidades e status que os distinguem dos demais não proprietários. A teoria Weberiana, ao possibilitar que outros fatores além da propriedade delimitem as classes, parece mais adequada para a compreensão dessas camadas intermediárias.

De qualquer forma, até hoje, essas duas correntes servem como as principais bases a partir das quais a definição das classes e, mais especificamente, da(s) classe(s) média(s) são orientadas. Atualmente, podemos encontrar diversos termos que tentam dar conta das camadas médias, como "service class" (GOLDTHORPE, 2000), "new class" (GOULDNER, 1979), "white collar" (MILLS, 1951), "managerial class" (EHRENREICH \& EHRENREICH, 1978), "contradictory locations within class relation" (WRIGHT, 1976), etc. Os argumentos utilizados para definir a(s) classe(s) média(s) são diversos, assim como são várias as discordâncias nesse campo.

Trataremos aqui dos esforços de John Goldthorpe e Erik Olin Wright - dois dos mais importantes autores contemporâneos sobre estratificação social - na tentativa de compreender esse debate.

Mais próximo do arcabouço weberiano, o inglês John Goldthorpe tem utilizado o termo service class ${ }^{4}$ (GOLDTHORPE, 2000) para se referir à(s) classe(s) média(s). A service class se distinguiria da classe trabalhadora por possuir uma regulação de emprego construída sobre outras bases. Devido à especificidade de seus ativos humanos e também devido às enormes dificuldades de se monitorar e controlar o seu tipo de trabalho, seu emprego e remuneração seriam mais estáveis e menos diretamente relacionados à produção. Além disso, contariam com benefícios adicionais - melhores salários, oportunidades de carreira, etc. - que não estariam presentes no caso do labour contract.

Fariam parte da service class, principalmente, os profissionais, administradores, gerentes e técnicos de alto nível. Na classe trabalhadora, estariam basicamente os trabalhadores manuais não qualificados e trabalhadores rurais. Entretanto, algumas categorias são encaixadas por Goldthorpe (2000) em posições intermediárias, mistas, como os empregados não manuais de rotina, trabalhadores manuais qualificados, técnicos e supervisores.

Além de Goldthorpe, outro nome que vem se consolidando como um dos mais importantes dentro dessa discussão é o do norte-americano Erik Olin Wright. Seu trabalho tem o mérito de procurar ajustar a teoria marxista à análise das sociedades contemporâneas, possibilitando estudar os setores médios, a partir do legado teórico de Marx.

Wright (1993) constrói sua classificação através da repartição de diferentes ativos: meios de produção, habilidades e organização. Cada um desses três 
tipos de ativos funcionaria como um dos eixos a partir dos quais as classes seriam delimitadas. Dessa maneira, uma mesma classe poderia estar em posições distintas nos diferentes eixos. As classes médias se caracterizariam, justamente, por estarem em posições contraditórias em relação aos diferentes ativos. Não seriam proprietárias dos meios de produção (com exceção dos pequenos empregadores), mas possuiriam habilidades e/ou estariam em posição privilegiada no que se refere à organização. Para Wright, fariam parte das classes médias os pequenos empregadores, gerentes, supervisores e trabalhadores manuais qualificados.

Ao contrário de Goldthorpe, que confere um caráter unitário à service class, Wright não enxerga uma única, mas sim várias classes médias. Além disso, enquanto a classificação de Wright se baseia nos ativos e está diretamente ligada ao caráter do trabalho exercido pelos diferentes grupos no processo produtivo, a classificação de Goldthorpe se baseia no contrato de trabalho e na situação de mercado das diferentes classes.

Os trabalhos citados ficam longe de esgotar a discussão contemporânea acerca da definição de classe(s) média(s) ${ }^{5}$. Como já foi dito, a discussão é enorme e requer um longo espaço para que seja tratada de forma abrangente (SAVAGE et al., 1995). O principal ponto que gostaríamos de destacar aqui é o fato de esses trabalhos definirem a(s) classe(s) média(s) por outros critérios que não a renda. Goldthorpe, por exemplo, a(s) define através do tipo de contrato de trabaIho, enquanto Wright leva em consideração fatores como habilidades e posição na organização. Ambos, entretanto, constroem seus "esquemas de classe" por meio das informações sobre as características ocupacionais dos indivíduos, e é esse ponto que gostaríamos de destacar.

Assim, na literatura sociológica sobre estratificação podemos verificar a importância que é atribuída à ocupação dos indivíduos, pois permitem melhor identificar a situação de classe dos mesmos - dada, segundo Weber (1979), pelo componente causal específico de suas chances de vida, na medida em que esse componente é representado, exclusivamente, por interesses econômicos, na posse de bens e oportunidades de rendimentos, sob as condições do mercado de produtos ou do mercado de trabalho ${ }^{6}$.

Nesse sentido, a(s) classe(s) média(s) costumam ser identificadas, por exemplo, pelas situações de mercado e trabalho que formam a service class, de Goldthorpe (2000), ou os trabalhadores de colarinho branco, de Mills (1951). Ou seja, dizem respeito a agregados de indivíduos/ocupações que partilham de situações de classe semelhantes, de uma maneira geral localizadas entre os grandes empregadores e os trabalhadores manuais.
5. Não devemos nos esquecer dos trabalhos de Gouldner (1979), Dahrendorf (1950) e Savage et al. (1996).

6. A discussão em torno da definição de "classe" é extensa (SCALON, 1999; LAREAU \& DALTON, 2008); adotamos, aqui, uma perspectiva mais próxima do campo Weberiano. 
7. No Brasil, são diversos os trabaIhos que já haviam tocado no tema da classe média (FERNANDES, 1975; ALBUQUERQUE, 1977; QUADROS, 1985; ROMANELLI, 1986; OLIVEIRA, 1988; O `DOUGHERTY, 1988; BONELLI, 1989; FIGUEIREDO, 2004, entre outros). Para uma revisão dessa literatura, ver Pochman et al. (2006).
Não apenas por seguir uma tradição sociológica, as características ocupacionais são importantes porque permitem melhor classificar os indivíduos de acordo com suas chances de vida - afinal, os horizontes (acesso a oportunidades, direitos efetivos, interesses estratégicos, etc.) de um engenheiro, em início de carreira, e de um técnico em eletromecânica já consolidado no mercado, ambos com a mesma renda, podem ser bem diferentes (QUADROS, 2003) -, possibilitam operar a articulação entre as múltiplas dimensões analíticas implicadas em uma análise de classes (SOBRINHO, 2011), e sustentam análises sobre "desigualdades duráveis" e seus mecanismos institucionais de reprodução (TILLY, 1999). Até mesmo o prêmio Nobel de Economia, Amartya Sen, evidencia a incompletude das análises de renda (SEN, 2001). Dessa forma, é possível perceber os limites desse tipo de análise também, ou principalmente, quando se trata do estudo sobre classes e, no caso, sobre a classe média.

\section{Classe Média no Brasil}

No Brasil, também podemos encontrar alguns estudos que definem a(s) classe(s) média(s) através de agregados ocupacionais. Os importantes trabalhos de Quadros (1985, 1991, 2003), por exemplo, se baseiam na obra de Mills (1951), a fim de definir a(s) classe(s) média(s) no Brasil. Dessa forma, a(s) identifica através das informações a respeito das ocupações dos indivíduos, tomando a(s) classe(s) media(s), eminentemente, como agregado(s) de ocupações não manuais. Caminho semelhante é seguido por Sobrinho (2011), ao tecer suas críticas em relação ao critérios utilizados por Neri (2008) a fim de definir a classe média. E, também, Pochman et al. (2006), em análise igualmente influenciada pelos estudos de Quadros - anteriormente citados -, procura enfatizar a definição da(s) classe(s) média(s) através dos agregados de ocupações ${ }^{7}$.

Até meados do século XIX, o Brasil contava com uma estrutura social pouco diversificada, herdada de seu passado colonial como economia escravista agroexportadora. Nessa época, podíamos encontrar, nas cidades brasileiras - especialmente no eixo Rio de janeiro/São Paulo - pequenos grupos de profissionais liberais, militares, empregados públicos e trabalhadores do comércio que, juntos, somavam apenas um pouco mais de 700 mil pessoas ou aproximadamente $7 \%$ da população em idade ativa total (BARBOSA, 2003). Com o desenvolvimento obtido, a partir de então, é que as classes médias começaram a se desenvolver, formando estratos socialmente significativos nas principais cidades brasileiras do início do século XX. Mas, somente a partir de 1930 - através do processo de substituição de importações -, é que a base econômica das classes médias pôde se expandir substancialmente. 
Entre 1930 e 1980, o Brasil sofreu intenso processo de urbanização, expansão econômica e industrialização. Durante esse período, a classe média brasileira se expandiu vigorosamente em virtude da diversificação da estrutura social, com a criação de ocupações intermediárias e crescimento da burocracia e dos serviços oferecidos pelo Estado. Concomitantemente, o perfil da classe média brasileira também foi mudando, ao longo desse período, diminuindo a participação de pequenos proprietários e aumentando o percentual de assalariados. Esse processo de desenvolvimento da classe média brasileira, em meados do século XX, é muito bem descrito por Quadros (1991).

A partir da década de 1980 até o ano 2000, no entanto, com o arrefecimento da economia e as mudanças estruturais no mercado de trabalho, podemos identificar alterações na classe média. Parte dos tradicionais empregados intermediários no interior das grandes empresas foi sendo substituída por serviços terceirizados e a crescente concorrência externa levou ao enxugamento do quadro de funcionários ou a perdas salariais. Além disso, também se buscou diminuir o peso do Estado através de privatizações e redução do aparelho burocrático. Como resultado, cresceu significativamente a participação dos pequenos proprietários - com o correlato decréscimo dos assalariados -, diminuiu o setor industrial e aumentou o setor de serviços e comércio no seio da classe média (POCHMANN, 2006).

Nas próximas seções buscaremos analisar a(s) classe(s) média(s) brasileira(s) da última década, tendo como pano de fundo a discussão em torno de seu suposto crescimento (quando mensurada através da renda). Para tanto, utilizaremos os dados da Pesquisa Nacional por Amostra de Domicílios (PNADs), do Instituto Brasileiro de Geografia e Estatística ${ }^{8}$.

\section{Classes Médias no Brasil da Última Década}

O estudo coordenado por Neri (2008) divide a sociedade brasileira em 5 classes $(A, B, C, D, e E)^{9}$, cujos limites são dados pela renda. Da "Classe $E$ ", fazem parte

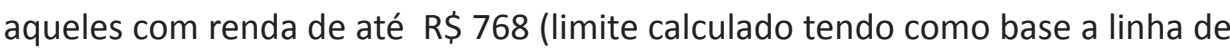
miséria ${ }^{10}$ ); entre $\mathrm{R} \$ 768$ e $\mathrm{R} \$ 1.064$ (calculado com base na mediana da distribuição ${ }^{11}$ ) estão aqueles que fazem parte da "Classe D"; a chamada nova classe média, "Camada C", é composta pelos que têm renda entre $\mathrm{R} \$ 1.064$ e $\mathrm{R} \$ 4.591$ (nono decil da distribuição); por fim, fazem parte da elite nacional, "Classe A \& B", aqueles com renda de no mínimo R\$ 4.591. Como já dito, os limites definidores das classes são dados somente por valores de renda, tomando como referência algumas medidas como mediana, decis, ou linha de miséria.
8. As PNADs são aplicadas todos os anos, com exceção daqueles em que os Censos são aplicados $(1980,1991$, 2000, 2010). Sua amostra é representativa da população brasileira como um todo, e suas variáveis trazem um grande volume de informações a respeito de temas como renda, escolaridade, ocupação, localização geográfica, informações familiares e domiciliares, etc. Trata-se, portanto, de uma das bases de dados mais utilizadas no Brasil.

9. Geralmente, as classes "A" e "B" são trabalhadas juntas, formando a classe "A \& B", ou "AB".

10. Definida e calculada pelo Centro de Políticas Sociais (FERREIRA, NERI, \& LANJOUW, 2003).

11. Todos os limites foram calculados levando-se em consideração a renda familiar total mensal per capita. Mas os valores apresentados são os equivalentes em renda total domiciliar mensal para o ano de 2006. 
12. A sigla EGP advém das iniciais dos nomes dos criadores desse esquema (ERIKSON, GOLDTHORPE \& PORTOCARERO, 1979).

13. Apesar de reconhecer a importância teórica da separação dos grandes empregadores, Goldthorpe (2000) sustenta que, devido a limitações amostrais, na maior parte dos estudos empíricos se torna difícil separá-los em um grupo específico.

14. "The employment relationship regulated by a labor contract entail a relatively shortterm and specific exchange of money for effort. Employees supply more-or-less discrete amount of labor (...) in return for wages which are calculated on a 'pie$c e^{\prime}$ or 'time' basis. In contrast, employment relationships (...) involves a longterm and generally more diffuse exchange. Employees render service to their employing organization in return for 'compensation', which takes the form not only of reward for work done, through a salary and various perquisites, but also comprises important prospective elements - for example, salary increments (...), pension rights (...) well-defined career opportunities." (ERIKSON \& GOLDTHORPE 1993, p. 41).
Entre 2002 e 2009, a participação da "Classe C" - que vem sendo chamada de nova classe média -, no recorte estudado, passou de 45,4\% para 54,2\%. A "Classe A \& B" correspondia a $13 \%$ do recorte, em 2002, passando para $17 \%$, em 2009. A “Classe D", que, em 2002, respondia por 15,5\% do recorte, em 2009 cai para $12,2 \%$. Por fim a "Classe E" apresentou uma substantiva diminuição, indo de 26,1\%, em 2002, para 16,5\%, em 2009. Desse modo, percebemos uma melhora na distribuição de renda, com os grupos de menor renda diminuindo sua participação e os grupos de renda média e alta intensificando sua presença. Devemos destacar a notável queda da participação da "Classe E" e também o correlato aumento da "Classe C".

Diante de dados dessa natureza, vem sendo difundida a ideia de que o Brasil estaria se tornando, ou já teria se tornado, um país de classe média, o que teria consequências em relação às demandas da população, seu estilo de vida, visões de mundo, aspirações, orientações políticas, etc. No entanto, acreditamos que outras maneiras de mensurar a classe média, especialmente aquelas que fazem parte da tradição sociológica, baseadas nas informações sócio-ocupacionais, poderiam nos ajudar a interpretar os recentes movimentos das classes médias no interior da estrutura social brasileira.

Faremos uso, aqui, do esquema de classificação desenvolvido por Erikson, Goldthorpe e Portocarero (1979), comumente conhecido como EGP ${ }^{12}$. O esquema de classes EGP é construído a partir das informações ocupacionais e seu objetivo é "diferenciar posições dentro do mercado de trabalho e das unidades produtivas" (ERIKSON, GOLDTHORPE \& PORTOCARERO, 1979, p. 37). Na contrução desse esquema, o primeiro critério de distinção separa empregadores, autônomos e empregados ${ }^{13}$. O segundo critério é aplicado somente aos empregados que, em geral, conformam a maior parte da população ocupada nas sociedades modernas -, e separa as ocupacões levando em conta o tipo de contrato de trabalho. Nesse sentido, o eixo de classificação vai do puro labor contract, que em geral se faz presente entre trabalhadores manuais ou não manuais de baixo status, até o service relationship, tipicamente aplicado ao caso dos profissionais, administradores e gerentes ${ }^{14}$.

Tabela 01 - Conversão da Versão de 11 para a Versão de 6 categorias do Esquema EGP

\begin{tabular}{|c|c|}
\hline EGP 11 & EGP 6 \\
\hline $\begin{array}{c}\text { I - Higher-grade Profs \& Adm } \\
\text { II - Lower-grade Prof \& Adm }\end{array}$ & Profissionais e Administradores \\
\hline $\begin{array}{c}\text { IIla - Higher-grade Routine non-manual } \\
\text { IIIb -Lower-grade Routine non-manual work }\end{array}$ & Trabalhadores Não-Manuais de Rotina \\
\hline
\end{tabular}




\begin{tabular}{|c|c|}
\hline $\begin{array}{c}\text { IVa - "Small" proprietors, with employees } \\
\text { IVb - "Small" proprietors, without employees }\end{array}$ & Pequenos Proprietários \\
\hline $\begin{array}{c}\text { V - Technicians and superv. manual work } \\
\text { VI - Skilled manual workers }\end{array}$ & Trabalhadores Manuais Qualificados \\
\hline VIla -Semi- \& unskilled manual workers & Trabalhadores Manuais não Qualificados \\
\hline IVc - Rural employers & \\
VIIb - Agricultural Workers & Rural \\
\hline
\end{tabular}

Fonte: Bergman e Joye (2001, elaboração própria)

No que se refere às camadas médias, a primeira categoria - profissionais e administradores - é composta pelas posições de alto nível dentro da nova classe média, como dirigentes, diretores, gerentes, especialistas, técnicos e profissionais de status elevado em geral (engenheiros, advogados, médicos, etc). Já, dentro da segunda categoria - trabalhadores não manuais de rotina -, se encontram, por exemplo, secretários, professores do ensino fundamental, delegados de polícia, escritores, jornalistas e vendedores de lojas. Juntando esses dois primeiros grupos, poderíamos falar de uma nova classe média (ou white collars), no sentido atribuído por Mills (1951).

Para Goldthorpe (2000), no entanto, os trabalhadores não manuais de rotina estariam mais próximos do labour contract do que do service relationship - esse último, típico dos profissionais e administradores. A classificação desse segmento (não manuais de rotina) entre classe média ou classe trabalhadora costuma gerar divergências (DEVINE, 1997; SANTOS, 2002). De qualquer maneira, parte da bibliografia e dos trabalhos empíricos já desenvolvidos no Brasil sobre esse segmento mostra que a divisão entre trabalho manual e não manual, e o desprezo em relação ao primeiro tipo, marcam profundamente a identidade das classes médias brasileiras (OWENSBY, 1999; SAES, 1985). Por essa razão inserimos os trabalhadores não manuais de rotina dentro das classes médias. Por fim, a classe dos pequenos proprietários - ou antiga classe média (MILLS, 1951) - é composta por dirigentes, gerentes, representantes comerciais, produtores, vendedores, entre outros; todos na posição de empregadores ou por conta própria.

Abaixo, temos a distribuição dos indivíduos do sexo masculino, com idade entre 24 e 60 anos, pelo esquema EGP com 6 classes:

Tabela 02 - Presença Relativa e Absoluta das Composições Sócio-Ocupacionais (EGP) no Brasil (2002-2009)

para indivíduos do sexo masculino, entre 24 e 60 anos de idade 


\begin{tabular}{|c|c|c|c|c|}
\hline \multirow{2}{*}{ EGP (6 classes) } & \multicolumn{4}{|c|}{ Ano de Referência } \\
\cline { 2 - 5 } & \multicolumn{2}{|c|}{2002} & \multicolumn{2}{|c|}{2009} \\
\cline { 2 - 5 } & $\mathrm{n}$. & $\%$ & $\mathrm{n}$. & $\%$ \\
\hline Profissionais e Administradores & 2835632 & 8,7 & 3461407 & 9,0 \\
\hline Trabalhadores não manuais de rotina & 4269793 & 13,1 & 5863331 & 15,2 \\
\hline Pequenos proprietários & 2986857 & 9,1 & 3024758 & 7,8 \\
\hline Trabalhadores manuais qualificados & 7552212 & 23,1 & 9296971 & 24,1 \\
\hline Trabalhadores não qualificados & 8621318 & 26,4 & 10410875 & 26,9 \\
\hline Rural & 6402854 & 19,6 & 6594503 & 17,1 \\
\hline Total & 32668666 & 100,0 & 38651845 & 100,0 \\
\hline
\end{tabular}

Fonte: PNADs, 2002, 2009 / IBGE (elaboração própria)

É importante observar que todas as classes crescem em termos absolutos, o que reflete o crescimento da população ocupada do Brasil nos últimos anos. No entanto, a participação relativa das classes na estrutura social não parece sofrer grandes modificações substantivas entre 2002 e 2009. As três primeiras categorias juntas (classes médias), em 2002, representavam 30,9\% do recorte estudado; oito anos depois, em 2009, esse percentual ficava em $32 \%$. No ano de 2002 , os profissionais e administradores somavam, junto aos trabalhadores não manuais de rotina, $21,8 \%$ da população ocupada; em 2009 , esse percentual sobe para $24,2 \%$. Já os pequenos proprietários respondiam por $9,1 \%$ da população ocupada em 2002, e em 2009 respondem por 7,8\%. Apesar dessas pequenas mudanças percentuais, acreditamos que o mais importante a ser destacado é a manutenção do patamar de participação da(s) classe(s) média(s) - quando mensuradas através de critérios sócio-ocupacionais - na estrutura social brasileira dos últimos anos. Mas, talvez, possamos notar pequenas mudanças no interior dessa classe:

Tabela 03 - Composição da Classe Média Brasileira (2002-2009) para indivíduos do sexo masculino, entre 24 e 60 anos de idade

\begin{tabular}{|c|c|c|}
\hline \multirow{2}{*}{ Classe(s) Média(s) } & \multicolumn{2}{|c|}{ Ano de Referência } \\
\cline { 2 - 3 } & 2002 & 2009 \\
\cline { 2 - 3 } & $\%$ & $\%$ \\
\hline Profissionais e Administradores & 28,1 & 28,0 \\
\hline Trabalhadores não Manuais de Rotina & 42,3 & 47,5 \\
\hline Pequenos Proprietários & 29,6 & 24,5 \\
\hline Total & 100 & 100 \\
\hline
\end{tabular}

Fonte: PNADs, 2002, 2009 / IBGE (elaboração própria) 
A tabela acima parece evidenciar uma reversão das tendências indicadas por Pochmann (2006) para as duas últimas décadas do século passado no Brasil, de que a proporção da classe média proprietária se aproximava da dos assalariados no interior da classe média. Em 2002, quase 30\% da classe média era composta de pequenos proprietários; em 2009, esse percentual cai para $24,5 \%$. Por outro lado, a participação dos trabalhadores não manuais de rotina passa de $42,3 \%$, em 2002, para 47,5\%, em 2009. Contudo, é importante salientar que essa categoria é bastante heterogênea e incorpora ocupações com baixo prestígio, autonomia no emprego, estabilidade e renda, embora sejam white collar. Já os profissionais e administradores se mantiveram no patamar de $28 \%$. Cresceu, portanto, a proporção da classe média assalariada, mas somente no que diz respeito às ocupações de menor status.

Os dados mostrados até o momento evidenciam que diferentes maneiras de se mensurar a(s) classe(s) média(s) podem levar a resultados e conclusões bastante distintos. Quando definida através da renda, como a "Classe C" (NERI, 2008), apresenta crescimento substantivo nos últimos anos. Porém, quando definida através de critérios como tipo de ocupação e posição no mercado de trabalho, é a sua manutenção que se destaca, com pequenas mudanças em sua composição. Na seção seguinte, veremos a evolução de algumas características dessa classe média nos últimos anos.

Características da Classe Média no Brasil da Última Década: renda, escolaridade, raça e consumo

Como já foi dito, nos últimos anos o Brasil apresentou um contexto econômico bem favorável, onde muitos indivíduos e famílias saltaram das faixas de renda inferiores para faixas intermediárias. A tabela abaixo nos ajuda a entender quais classes foram as mais beneficiadas em relação ao aumento da renda, entre 2002 e 2009:

Tabela 04 - Média da Renda* por Composição Sócio-Ocupacional (EGP) no Brasil (2002-2009)

para indivíduos do sexo masculino, entre 24 e 60 anos de idade

\begin{tabular}{|c|c|c|c|c|}
\hline \multirow{2}{*}{ EGP (6 classes) } & \multirow{2}{*}{ ano } & \multicolumn{3}{|c|}{ renda } \\
\hline & & média & var. $\%$ & desvio-padrão \\
\hline Profissionais e Administradores & $\begin{array}{l}2002 \\
2009\end{array}$ & $\begin{array}{l}3522,9 \\
3616,4\end{array}$ & 2,7 & $\begin{array}{l}3605,1 \\
7129,4\end{array}$ \\
\hline Trabalhadores não manuais de rotina & $\begin{array}{l}2002 \\
2009\end{array}$ & $\begin{array}{l}1317,8 \\
1339,2\end{array}$ & 1,6 & $\begin{array}{l}1507,1 \\
1471,0\end{array}$ \\
\hline Pequenos proprietários & $\begin{array}{l}2002 \\
2009\end{array}$ & $\begin{array}{l}2349,5 \\
2448,4\end{array}$ & 4,2 & $\begin{array}{l}3474,4 \\
3983,7\end{array}$ \\
\hline Trabalhadores manuais qualificados & $\begin{array}{l}2002 \\
2009\end{array}$ & $\begin{array}{c}959,3 \\
1086,5\end{array}$ & 13,3 & $\begin{array}{l}883,8 \\
939,6\end{array}$ \\
\hline
\end{tabular}

\footnotetext{
* Renda do trabaIho principal/preços constantes, 2009 (INPC)
} 


\begin{tabular}{|c|c|c|c|c|}
\hline Trabalhadores não qualificados & $\begin{array}{l}2002 \\
2009\end{array}$ & $\begin{array}{l}817,7 \\
897,6\end{array}$ & 9,8 & $\begin{array}{l}821,2 \\
863,3\end{array}$ \\
\hline Rural & 2002 & 508,5 & 15,0 & 1381,0 \\
585,0 & 2009 & & 1134,3 \\
\hline
\end{tabular}

Fonte: PNADs, 2002, 2009 / IBGE (elaboração própria)

Em primeiro lugar, chama atenção a enorme distância, em termos de renda média, que separa as classes, especialmente os pequenos proprietários e, principalmente, os profissionais e administradores, em relação às outras classes. Vemos, também, que a classe dos trabalhadores não manuais de rotina, que poderíamos tomar como o centro de gravidade da nova classe média de Mills (1951), se encontra, em termos de rendimentos, mais próxima dos trabalhadores manuais do que dos profissionais e administradores ou pequenos empregadores.

Em segundo lugar, vemos que quase todas as classes apresentaram aumento em suas rendas no período estudado. No entanto, chama a atenção o fato de que as classes que mais se beneficiaram, proporcionalmente, desse aumento nos rendimentos, foram aquelas localizados na metade inferior da estrutura social - no setor dos trabalhadores manuais. Resultado semelhante pode ser encontrado, também, em Silva (2003), para as décadas de 1980 e, principalmente, 1990, quando também parece ter havido diminuição das distâncias de renda entre as classes.

Enquanto, por exemplo, a renda média dos profissionais e administradores crescera 2,7\%, entre 2002 e 2009, a dos trabalhadores manuais qualificados crescera $13,3 \%$, a dos manuais não qualificados crescera $9,8 \%$, e o crescimento da renda dos trabalhadores rurais ficara em $15 \%$.

Algumas conclusões mais gerais devem ter tiradas dos dados expostos acima. $\mathrm{A}(\mathrm{s})$ classe(s) média(s) obtém rendimentos nitidamente mais elevados (com exceção dos trabalhadores não manuais de rotina) que as classes de trabalhadores manuais. Apesar disso, nos últimos anos as classes que mais se beneficiaram com aumento de renda, proporcionalmente falando, foram aquelas mais próximas da base da estrutura social brasileira - de trabalhadores manuais. Nesse sentido podemos dizer que, no que diz respeito aos rendimentos, apesar das enormes desigualdades ainda existentes, houve, nos últimos anos, uma aproximação entre a(s) classe(s) média(s) e os trabalhadores manuais.

Uma importante característica das camadas médias é seu grau de fechamento social (DEVINE, 1997). Vejamos como isso tem se dado em relação à escolaridade "exigida" para fazer parte desse estrato no Brasil: 
Tabela 05 - Média e Faixa de Anos de Estudo por Composição Sócio-Ocupacional (EGP) no Brasil (2002-2009)

para indivíduos do sexo masculino, entre 24 e 60 anos de idade

\begin{tabular}{|c|c|c|c|c|c|c|c|}
\hline \multirow{3}{*}{ EGP (6 classes) } & \multirow{3}{*}{ Ano } & \multicolumn{6}{|c|}{ Anos de Escolaridade } \\
\hline & & \multirow[t]{2}{*}{ Média } & $\begin{array}{l}\text { de } 0 \\
\text { a } 4\end{array}$ & $\begin{array}{c}\text { de } 5 \\
\text { a } 8\end{array}$ & $\begin{array}{c}\text { de } 9 \text { a } \\
12\end{array}$ & $\begin{array}{c}\text { mais } \\
\text { de } \\
12\end{array}$ & Total \\
\hline & & & $\%$ & $\%$ & $\%$ & $\%$ & $\%$ \\
\hline \multirow{2}{*}{ Profissionais e Administradores } & 2002 & 13,4 & 5,8 & 8,2 & 24,1 & 61,9 & \multirow{2}{*}{100} \\
\hline & 2009 & 14,2 & 2,5 & 4,9 & 20,8 & 71,8 & \\
\hline \multirow{2}{*}{$\begin{array}{l}\text { Trabalhadores não manuais de } \\
\text { rotina }\end{array}$} & 2002 & 10,7 & 11,8 & 23,3 & 44,4 & 20,6 & \multirow{2}{*}{100} \\
\hline & 2009 & 11,7 & 7,0 & 15,3 & 49,1 & 28,5 & \\
\hline \multirow{2}{*}{ Pequenos proprietários } & 2002 & 9,3 & 25,6 & 24,7 & 31,5 & 18,2 & \multirow{2}{*}{100} \\
\hline & 2009 & 10,0 & 19,6 & 22,8 & 37,3 & 20,4 & \\
\hline \multirow{2}{*}{ Trabalhadores manuais qualificados } & 2002 & 7,5 & 36,6 & 34,9 & 24,1 & 4,7 & \multirow{2}{*}{100} \\
\hline & 2009 & 8,8 & 25,0 & 30,0 & 37,4 & 7,7 & \\
\hline \multirow{2}{*}{ Trabalhadores não qualificados } & 2002 & 6,8 & 44,1 & 33,9 & 19,8 & 2,2 & \multirow{2}{*}{100} \\
\hline & 2009 & 7,9 & 32,2 & 32,6 & 30,8 & 4,4 & \\
\hline \multirow{2}{*}{ Rural } & 2002 & 4,0 & 78,9 & 15,0 & 4,9 & 1,2 & \multirow{2}{*}{100} \\
\hline & 2009 & 4,9 & 68,1 & 19,1 & 10,1 & 2,7 & \\
\hline
\end{tabular}

Fonte: PNADs, 2002, 2009 / IBGE (elaboração própria)

A média de anos de estudo completos cai conforme caminhamos do topo da hierarquia até sua base, e há uma clara tendência de aumento da escolaridade no interior de todos os grupos, entre 2002 e 2009.

A coluna com o percentual de indivíduos com 12 ou mais anos de estudo torna nítida uma barreira para entrada na classe média e outra dentro da própria classe média. É importante dizer que, no Brasil, ter 12 anos de estudo significa ter cursado ao menos 1 ano no Ensino Superior. Se atentarmos para o fato de que, entre a população brasileira com mais de 10 anos de idade, aqueles que o fizeram não chegavam a somar $10 \%$ em 2009, fica patente a importância de se atingir esse nível de escolaridade.

Dentre os grupos que não fazem parte das classes médias, o maior percentual de indivíduos com 12 ou mais anos de estudo foi o dos trabalhadores manuais qualificados em 2009: 7,7\% apenas. Entre os pequenos proprietários, 20,4\% tinham pelo menos 12 anos de estudo, 28,5\% entre os trabalhadores não manuais de rotina, e nada menos que $71,8 \%$ nos profissionais e administradores. Aliás, esse último grupo parece o mais fechado a esse respeito - da escolaridade -, mesmo em relação aos outros grupos de classe média. Em 2009, mais de $90 \%$ de seus componentes tinham pelo menos 9 anos de estudo; entre os não manuais de rotina, essa cifra ficava em $77 \%$, e em apenas $57 \%$, entre os pequenos proprietários. Enquanto nesses dois últimos grupos, há uma participação "razoável" 
15. Para um resumo desse debate, ver Ribeiro (2006). de todas as faixas de escolaridade, no primeiro há uma concentração significativa na faixa mais elevada.

Uma importante característica da sociedade brasileira é sua estratificação por cor ou raça, e há um enorme debate a esse respeito por aqui ${ }^{15}$. Acreditamos que a distribuição por raça possa ser um importante indicador do grau de fechamento social das classes médias. A tabela abaixo traz alguns dados interessantes a esse respeito:

Tabela 06 - Cor ou Raça por Composição Sócio-Ocupacional (EGP) no Brasil (2002-2009) para indivíduos do sexo masculino, entre 24 e 60 anos de idade

\begin{tabular}{|c|c|c|c|c|}
\hline \multirow{2}{*}{ EGP (6 classes) } & \multirow{2}{*}{ Ano } & \multicolumn{3}{|c|}{ Cor ou Raça } \\
\cline { 3 - 5 } & & Branco & Negro* & Total \\
\cline { 3 - 5 } & & $\%$ & $\%$ & $\%$ \\
\hline \multirow{2}{*}{ Profissionais e Administradores } & 2002 & 76,3 & 23,7 & \multirow{2}{*}{100} \\
\hline \multirow{2}{*}{ Trabalhadores não manuais de rotina } & 2009 & 71,7 & 28,3 & \\
\hline \multirow{2}{*}{ Pequenos proprietários } & 2002 & 62,1 & 37,9 & \multirow{2}{*}{100} \\
& 2002 & 67,0 & 33,0 & \multirow{2}{*}{100} \\
\hline \multirow{2}{*}{ Trabalhadores manuais qualificados } & 2009 & 62,1 & 37,9 & \\
\hline \multirow{2}{*}{ Trabalhadores não qualificados } & 2002 & 54,2 & 45,8 & \multirow{2}{*}{100} \\
& 2002 & 57,9 & 52,1 & \\
\hline \multirow{2}{*}{ Rural } & 2009 & 43,2 & 56,0 & \multirow{2}{*}{100} \\
\hline \multirow{2}{*}{ Nann } & 2002 & 43,2 & 56,8 & \multirow{2}{*}{100} \\
\hline
\end{tabular}

Fonte: PNADs, 2002, 2009 / IBGE (elaboração própria)

Em 2009, o percentual de indivíduos, dentro do recorte utilizado, que se declararam negros foi de 51,1\% no total (em 2002 essa cifra era de 45,4\%). No entanto, em nenhum dos grupos de classe média, a participação dos negros chegou a $50 \%$. Entre os profissionais e administradores, ela não chega a $30 \%$, fica em $45 \%$ entre os trabalhadores não manuais de rotina, e não chega a $40 \%$ entre os pequenos proprietários. Em todas as outras classes, no entanto, ela ultrapassa os $50 \%$ em 2009 e ultrapassava 45,4\%, em 2002. Note que existe uma concentração de indivíduos da raça negra no setor rural e no manual não-qualificado.

Mais uma vez, dentro das classes médias, destaca-se a posição dos profissionais e administradores, que apresenta uma participação de mais de $70 \%$ de brancos em seu interior. Os dois outros grupos da classe média ficam mais próximos nesse quesito, com uma proporção um pouco maior de negros entre os trabaIhadores não manuais de rotina. 
Outra importante característica geralmente vinculada à(s) classe(s) média(s), analisada, por exemplo, por Mills (1951) e Bourdieu (2008), é seu padrão de consumo distinto, associado a uma reivindicação de um status superior ao dos trabalhadores manuais. No Brasil, O`Dougherty (1998) e Owensby (1994), por exemplo, evidenciam como o consumo tem sido um recurso central na formação e afirmação da identidade dessa classe.

A expansão do consumo entre a população brasileira tem sido muito debatida nos últimos anos. A tabela abaixo mostra o número e percentual de domicílios que possuíam determinados bens de consumo (telefone celular, microcomputador, geladeira, máquina de lavar roupa e carro), em 2002 e em 2009:

Tabela 07 - Percentual de Domicílios que Possuem Determinados Bens de Consumo, por Composição Sócio-Ocupacional (EGP) do Chefe de Domicílio no Brasil,

(2002-2009)

para chefes de domicílio entre 24 e 60 anos de idade

\begin{tabular}{|c|c|c|c|c|c|c|}
\hline \multirow{2}{*}{ EGP (6 classes) } & \multirow{2}{*}{} & \multicolumn{5}{|c|}{ Bens de Consumo } \\
\cline { 3 - 7 } & Ano & $\begin{array}{c}\text { Tele- } \\
\text { fone } \\
\text { Celu- } \\
\text { lar }\end{array}$ & $\begin{array}{c}\text { Micro- } \\
\text { com- } \\
\text { puta- } \\
\text { dor }\end{array}$ & $\begin{array}{c}\text { Gela- } \\
\text { deira }\end{array}$ & $\begin{array}{c}\text { Máqui- } \\
\text { na de } \\
\text { lavar } \\
\text { roupa }\end{array}$ & Carro* \\
\hline Profissionais e Administradores & 2002 & 77,0 & 58,0 & 98,5 & 71,4 & --- \\
& 2009 & 97,4 & 84,0 & 99,6 & 79,4 & 67,6 \\
\hline \multirow{2}{*}{ Trabalhadores não manuais de rotina } & 2002 & 53,4 & 23,8 & 96,7 & 49,0 & --- \\
& 2009 & 94,2 & 57,2 & 98,5 & 59,7 & 39,3 \\
\hline \multirow{2}{*}{ Pequenos Proprietários } & 2002 & 58,6 & 31,8 & 94,8 & 53,8 & --- \\
& 2009 & 91,6 & 57,1 & 97,2 & 62,3 & 50,9 \\
\hline \multirow{2}{*}{ Trabalhadores manuais qualificados } & 2002 & 36,8 & 11,8 & 93,3 & 34,5 & --- \\
& 2009 & 88,3 & 39,3 & 97,0 & 49,2 & 32,5 \\
\hline \multirow{2}{*}{ Trabalhadores não qualificados } & 2002 & 30,8 & 6,3 & 89,3 & 27,2 & --- \\
& 2009 & 85,7 & 29,2 & 94,9 & 38,6 & 25,1 \\
\hline \multirow{2}{*}{ Rural } & 2002 & 12,8 & 2,5 & 60,7 & 9,2 & --- \\
& 2009 & 56,9 & 9,4 & 80,1 & 14,8 & 16,7 \\
\hline \multirow{2}{*}{ Total } & 2002 & 38,9 & 16,4 & 87,3 & 35,2 & --- \\
& 2009 & 84,8 & 40,3 & 94,3 & 46,5 & 33,9 \\
\hline
\end{tabular}

Fonte: PNADs, 2002, 2009 / IBGE (elaboração própria)

Ao olharmos os totais da tabela acima, veremos que aumentou substancialmente o percentual de domicílios que possuem os bens de consumo analisados, de uma maneira geral, entre 2002 e 2009; nesse âmbito, se destaca a expansão da posse de celulares e microcomputadores.

Em relação a todos os itens, destaca-se a posição dos profissionais e administradores, que, invariavelmente, apresentam percentuais mais elevados que os 
demais grupos. Dentro da classe média, ainda, os pequenos proprietários e os trabalhadores não manuais de rotina só não ficam próximos em relação à posse de automóvel (50,9\%, para o primeiro grupo, e 39,3\%, para o segundo). Os domicílios chefiados por indivíduos de classes médias ainda apresentam percentuais mais elevados que aqueles dos trabalhadores manuais e do setor rural; mas, em 2002, a distância entre essas classes se mostrava bem maior do que em 2009. Em relação à posse de geladeiras, por exemplo, já quase não há distância entre os grupos - somente no setor rural ainda há um grande percentual de domicílios sem geladeira.

De todo modo, é importante chamar atenção que a medição do consumo apenas pela posse de bens apresenta limites. Uma análise sociológica mais completa demandaria o estudo das práticas de consumo, revelando padrões, tendências e gostos que podem ser bastante diferenciados entre indivíduos ou grupos de indivíduos que, no volume/quantidade, parecem similares.

Duas conclusões mais gerais devem ter tiradas dos dados expostos acima. Em primeiro lugar, notamos a distância entre as classes médias e as classes manuais tanto em relação aos rendimentos quanto em relação ao nível educacional, distribuição por raça de seus integrantes e posse de alguns bens de consumo. As classes médias obtêm rendimentos nitidamente mais elevados (com exceção dos trabalhadores não manuais de rotina), é mais fechada - em relação à educação e raça -, e tende a possuir mais bens de consumo. Apesar disso, nos últimos anos, as classes que mais se beneficiaram, proporcionalmente falando, com aumento de renda e do consumo, foram aquelas mais próximas da base da estrutura social brasileira.

Em segundo lugar, ficou claro também que, dentro da classe média, há importantes divisões. Destaca-se a posição dos profissionais e administradores com rendimentos elevados, alta proporção de brancos e com nível educacional elevado, e posse de bens de consumo em seus domicílios. Em contraposição, verifica-se a aproximação dos trabalhadores não manuais de rotina com os trabalhadores manuais - especialmente os qualificados. Aquele foi o grupo que proporcionalmente menos aumentou sua renda e que mais elevou a sua proporção de negros; também em relação à posse de automóvel, por exemplo, a distância entre esse grupo e os trabalhadores manuais qualificados era de apenas 6,8\%, em 2009. Nesse sentido, talvez, possamos dizer que, nos últimos anos, tenha havido uma aproximação entre a baixa classe média e os estratos mais qualificados da classe trabalhadora.

Conclusão: Brasil, um país de classe média? 
Como já tivemos a oportunidade de dizer, nos últimos anos vem sendo recorrentemente levantada a hipótese de que o Brasil estaria se tornando um país de classe média. O principal argumento utilizado para sustentar essa tese é o crescimento dos grupos de renda intermediários, particularmente o "Grupo C" - muitas vezes lido como a nova classe média (NERI, 2008) ${ }^{16}$.

No entanto, quando olhamos a composição sócio-ocupacional dessa "Classe C", vemos o quanto heterogênea ela é:

Tabela 08 - Composição Sócio-Ocupacional (EGP) por Classes de Renda* no Brasil (2002-2009)

para indivíduos do sexo masculino, entre 24 e 60 anos de idade

\begin{tabular}{|c|c|c|c|c|c|c|c|c|}
\hline \multirow{3}{*}{$\begin{array}{c}\text { Classes } \\
\text { de } \\
\text { Renda } \\
* *\end{array}$} & \multirow{3}{*}{ Ano } & \multicolumn{7}{|c|}{ EGP (6 CLASSES) } \\
\hline & & $\begin{array}{l}\text { Prof. e } \\
\text { Adm. }\end{array}$ & $\begin{array}{l}\text { Trab. ñ } \\
\text { manuais }\end{array}$ & $\begin{array}{l}\text { Peq. } \\
\text { Proprietá- } \\
\text { rios }\end{array}$ & $\begin{array}{l}\text { Trab. } \\
\text { manu- } \\
\text { ais }\end{array}$ & $\begin{array}{l}\text { Trab. ñ } \\
\text { qualifi- } \\
\text { cados }\end{array}$ & Rural & Total \\
\hline & & $\%$ & $\%$ & $\%$ & $\%$ & $\%$ & $\%$ & $\%$ \\
\hline$E$ & $\begin{array}{l}2002 \\
2009\end{array}$ & $\begin{array}{l}1,0 \\
0,7\end{array}$ & $\begin{array}{l}5,3 \\
4,4\end{array}$ & $\begin{array}{l}3,8 \\
3,1\end{array}$ & $\begin{array}{l}16,4 \\
14,5\end{array}$ & $\begin{array}{l}25,4 \\
25,5\end{array}$ & $\begin{array}{l}48,0 \\
51,9\end{array}$ & 100 \\
\hline D & $\begin{array}{l}2002 \\
2009\end{array}$ & $\begin{array}{l}2,2 \\
1,4\end{array}$ & $\begin{array}{l}10,6 \\
11,8\end{array}$ & $\begin{array}{l}5,3 \\
4,4\end{array}$ & $\begin{array}{l}27,6 \\
24,0\end{array}$ & $\begin{array}{l}32,8 \\
34,8\end{array}$ & $\begin{array}{l}21,5 \\
24,3\end{array}$ & 100 \\
\hline C & $\begin{array}{l}2002 \\
2009\end{array}$ & $\begin{array}{l}6,9 \\
5,5\end{array}$ & $\begin{array}{l}16,4 \\
17,7\end{array}$ & $\begin{array}{l}9,6 \\
6,9\end{array}$ & $\begin{array}{l}28,2 \\
28,8\end{array}$ & $\begin{array}{l}29,6 \\
30,4\end{array}$ & $\begin{array}{c}9,3 \\
10,6\end{array}$ & 100 \\
\hline$A B$ & $\begin{array}{l}2002 \\
2009\end{array}$ & $\begin{array}{l}34,2 \\
30,1\end{array}$ & $\begin{array}{l}17,9 \\
18,8\end{array}$ & $\begin{array}{l}20,3 \\
16,2\end{array}$ & $\begin{array}{l}13,1 \\
17,6\end{array}$ & $\begin{array}{l}10,9 \\
13,1\end{array}$ & $\begin{array}{l}3,6 \\
4,2\end{array}$ & 100 \\
\hline
\end{tabular}

Fonte: PNADs, 2002, 2009 / IBGE (elaboração própria)

Dentro da "Classe C", tanto em 2002, quanto em 2009, podemos encontrar desde profissionais e administradores até trabalhadores não qualificados e setores rurais, passando por pequenos proprietários, trabalhadores qualificados e não manuais de rotina. Os trabalhadores não qualificados obtêm a maior participação dentro desse grupo, com aproximadamente $30 \%$; em seguida, temos os trabalhadores manuais qualificados, com $28 \%$, não manuais de rotina (17\%), rurais (10\%), pequenos proprietários (6,9\%, em 2009$)$ e profissionais e administradores (5,5\%, em 2009).

As classes médias juntas (profissionais e administradores, trabalhadores não manuais de rotina e pequenos proprietários) respondiam por apenas 32,9\% da "Classe C", em 2002, e 30,1\%, em 2009. Isso é apenas um pouco mais do que a metade da participação dos trabalhadores manuais no interior desse grupo de renda: 59,2\%, em 2009. Ficam claras, dessa forma, as dificuldades de se falar no Brasil como um país predominantemente de classe média, tendo como base o crescimento expressivo dos grupos de renda intermediários nos últimos anos.
16. Ver Tabela 01, acima.

\footnotetext{
*Renda do trabalho principal/preços constantes, 2009 (INPC)

** E $(\mathrm{R} \$ 00,00-\mathrm{R} \$$ $140,00)$ / D $(R \$$ $141,00-R \$ 222,00)$ / C (R\$ 223,00- R\$ $964,00) / A B$ (mais de $\mathrm{R} \$ 965,00)$
} 
Pudemos observar, através dos dados expostos acima, a expansão do mercado de trabalho e crescimento da renda no Brasil, em particular para as classes inferiores da estrutura social. Mas não foi verificado aumento da participação das classes médias (entendidas através de uma classificação sócio-ocupacional) no seio da estrutura social brasileira nos últimos anos, entre 2002 e 2009.

Constatamos, também, que, nos últimos anos, a composição dessa classe média sofreu pequenas alterações, com a diminuição, no seu interior, da participação dos pequenos proprietários e aumento da participação dos trabalhadores não manuais de rotina - o que parece configurar uma reversão das tendências apontadas por Pochmann et al. (2006) para as duas últimas décadas do século $X X$. Além disso, os dados trabalhados também mostraram que as classes médias brasileiras são compostas em maior proporção por indivíduos brancos e de escolaridade médio-alta.

No interior das classes médias, os profissionais e administradores se destacam por sua renda elevada, alta proporção de indivíduos com nível superior e pequena proporção de negros. Já os trabalhadores não manuais de rotina, por outro lado, vêm se aproximando dos trabalhadores manuais qualificados tanto em termos de rendimentos, quanto em termos de composição racial. Nesse sentido, ao invés de falarmos de uma nova classe média poderíamos ponderar, talvez, sobre uma parcela da classe trabalhadora que, em relação a certas características, quase exclusivamente os rendimentos, estaria se aproximando dos setores mais baixos das classes médias. Torna-se uma importante questão, portanto, verificar até que ponto essa aproximação em termos de rendimentos (e poder de consumo) poderia levar a uma aproximação, ou até mesmo a uma assimilação, no campo social.

Abstract: The article analyses, from the perspective of class studies in Sociology, the argument of Brazilian economists about the emergence of a new middle class. To achieve this task, the paper brings the debate conducted in economics, in which class is defined by income, as well as the debate of the Sociology of Stratification, according to its different theoretical frameworks. Using data from PNADs 2002 and 2009, it argues that the changes in the classes structure were not significant to support the idea of existence of a new class, neither that there was a growth in the traditional middle class.

Keywords: Middle Class, Inequalities, Stratification, Income, Consumption

\section{Referências}

ALBUQUeRQUE, G. Classes médias e política no Brasil. Rio de janeiro: Paz e Terra, 1977. 
BARBOSA, A. A formação do mercado de trabalho no Brasil: da escravidão ao assalariamento. Campinas: Instituto de Economia/UNICAMP. 2003

BARROS, R. CARVALHO, M. FRANCO, S. MENDONÇA, R. Determinantes da Queda na Desigualdade de Renda no Brasil. IPEA. Texto para discussão no 1460, 2010.

BERGMAN, M.; JOYE, D. "Comparing Social Stratification Schemas: CAMSIS, CSP$\mathrm{CH}$, Goldthorpe, ISCO-88, Treiman, and Wright". Cambridge Studies in Social Research, 2001.

BONELLI, M. da G. A classe média, do "Milagre" à recessão: mobilidade social, expectativas e identidade coletiva. São Paulo: IDESP, 1989.

BOURDIEU, P. A Distinção: crítica social do julgamento. São Paulo, SP, Edusp, 2008.

BURRIS, V. "The Discovery of the New Middle Class". Theory and Society. 15, 1986, p. 317-349.

DAHRENDORF, R. Class and Class Conflict in Industrial Society. London: Routledge and nKegan Paul, 1959.

DEVINE, F. Social Class in America and Britain. Edinburgh University Press, 1997.

EHRENREICH, B. EHRENREICH, J. "The professional-managerial class", In: P. WALKER (ed.), Between Labour and Capital, New York: Monthly Review, 1979.

ERIKSON, R. GOLDTHORPE, J. The Constant Flux: a study of class mobility in industrial societies. Oxford: Oxford University Press, 1993.

ERIKSON, R. GOLDTHORPE, J. H. PORTOCARERO, L. “Intergenerational Class Mobility in Three Western European Societies". British journal of Sociology, n. 30, 1979 , p. 415-441.

FERNANDES, F. Capitalismo dependente e classes sociais na América Latina. 2.ed. Rio de Janeiro: Zahar Editora, 1975.

FIGUEIREDO, A. "Fora do Jogo: a experiência dos negros na classe média brasileira". In: Cadernos Pagu, jul/dez. 2004, no 23, p. 199-228.

GOLDTHORPE, J. H. "The Service Class Revisited" In: M. Savage; T. Butler (eds.) Social Change and the Middle Classes. London: UCL Press, 1995. 
GOLDTHORPE, J. H. et al. The Affluent Worker in the Class Structure. Cambridge: Cambridge University Press, 1969.

GOLDTHORPE, John H. "Social Class and the Differentiation of Employment Contracts". In: GOLDTHORPE, J. On Sociology: numbers, narratives, and the integration of research and theory. Oxford University Press, 2000.

GOULDNER, A. W. The Future of intellectuals and the Rise of the New Class. New York: Continuum.

LAREAU, A.; DALTON, C. (eds.) Social Class: how does it work? Russell Sage Foundation: New York, 2008, p. 25-64.

MALOUTAS. T. "Socio-Economic Classification Models and Contextual Difference: The 'European Sócio-economic Classes' (ESeC) from a South European Angle". South European Society \& Politics, Vol. 12n, n. 4, 2007, p. 443-460.

MARQUES, E.; SCALON, M. C.; OLIVEIRA, M. A. "Estrutura Social e Classe em Duas Metrópoles Brasileiras". In: SCALON, M. C. (org.) Ensaios de Estratificação. Belo Horizonte: Argumentum, 2009.

MILLS, C. W. White Collar. New York: Oxford University Press, 1951.

NERI, M. A Nova Classe Média. Rio de Janeiro: CPS, 2008.

O'DOUGHERTY, M. Middle Classes, Itd.: Consumption and class identity during Brazil's inflation crisis. New York: City University of New York, 1997.

OLIVEIRA, F. "Medusa ou as classes médias e a consolidação democrática”. In: REIS, F; O`DONNELL, G. (org.) A democracia no Brasil: dilema e perspectivas. São Paulo: Vértice, 1988.

OLIVEIRA, F. L. “Movilidad Social y Económica en Brasil: una nueva clase media?” In: FRANCO, R. HOPENHAYN, M. LEÓN, A. (orgs.) Las Clases Medias en América Latina: retrospectiva y nuevas tendencias. Siglo xxi editores, CEPAL, 2010.

OWENSBY, B. Intimate Ironies: modernity and the making of the new middle class lives in Brazil. Standford: Standford University Press, 1999.

POCHMANN, M. AMORIM, R. SILVA, R. GUERRA, A. Classe Média: desenvolvimento e crise. São Paulo/SP. Cortez Editora, 2006.

QUADROS, W. "A evolução recente das classes sociais no Brasil". In: HENRIQUE, W. PRONI, M. (org.). Trabalho, Mercado e Sociedade. São Paulo: UNESP; Campinas: IE/UNICAMP, 2003.

. A nova classe média brasileira. Campinas: IE/UNICAMP, 1985. 
. O "milagre brasileiro" e a expansão da nova classe média. campinas: IE/UNICAMP, 1991.

RIBEIRO, C. A. C. "Classe, raça e Mobilidade Social no Brasil". In: DADOS - Revista de Ciências Sociais, volume 49 n. 4, 2006.

ROEMER, J. A General Theory of Exploitation and Class. Cambridge: Harvard University Press, 1982.

ROMANELLI, G. Famílias de camadas médias. A trajetória da modernidade. Tese de Doutorado, USP, 1996.

SAES, D. Classe Média e Sistema Político no Brasil. São Paulo: T.A Queiroz, 1984.

SANTOS, J. A. F. Estrutura de Posições de Classe no Brasil: mapeamento, mudanças e efeitos na renda. Rio de Janeiro: IUPERJ, 2002.

SAVAGE, M.; BARLOW, J.; DICKENS, P.; FIELDING, T. Property, bureaucracy and culture: middle-class formation in contemporary britain. Reprinted. London: Rouledge, 1995.

SEN, A. Desigualdade Reexaminada. São Paulo, Record, 2001.

SILVA, N. do V. "Os Rendimentos Pessoais" In: Hasenbalg, C. Silva, N. (orgs.) Origens e Destinos: desigualdades sociais ao longo da vida. Rio de Janeiro: Topbooks, 2003.

SOBRINHO, G. G. de F. X. "'Classe C' e sua alardeada ascensão: nova? Classe? Média? Índice Econômico". FEE, v. 38, n. 4, 2011, p. 57-80.

SOUZA, A.; LAMOUNIER, B. A Classe Média Brasileira: ambições, valores e projetos de sociedade. Rio de Janeiro/RJ: Elsevier, 2001.

SOUZA, J. Os batalhadores brasileiros. Nova classe média ou nova classe trabaIhadora? Belo Horizonte: UFMG, 2010.

TORRES, H. "Quem é classe média no Brasil". Gazeta Mercantil - Opinião $23 / 2 / 2004$

WRIGHT, E. O. "What is Middle About the Middle Class?" In: Roemer, John (org) Analytical Marxism. Cambridge University Press, 1986.

. Class, Crisis and the State. London: New Left Books, 1978.

. The Debate on Classes. London: Verso, 1989. 